\title{
A VARIAÇÃO LINGUÍSTICA EM DICIONÁRIOS ESCOLARES: 0 ESTADO DA ARTE
}

\section{LINGUISTIC VARIATION IN SCHOOL DICTIONARIES: STATE OF THE} ART

Américo Venâncio Lopes Machado Filho*

RESUMO: O presente trabalho tem por objetivo discutir o estado da arte no que concerne ao registro da variação linguística em dicionários escolares brasileiros contemporâneos, nomeadamente nos que se destinam ao ensino médio, com vistas a estabelecer um diagnóstico e, consequentemente, uma estratégia de ação, associada a um trabalho lexicográfico renovado para o adequado tratamento da variação lexical em língua portuguesa.

PALAVRAS-CHAVE: Variação linguística. Léxico. Dicionários escolares brasileiros.

ABSTRACT: The present work aims to discuss the state of the art of linguistic variation in contemporary Brazilian dictionaries, in particular those intended for High School, in order to establish a diagnosis and, consequently, a strategy of action, associated to a renewed lexicographic work, more appropiate for the treatment of Portuguese lexical variation.

KEYWORDS: Linguistic variation. Lexicon. Brazilian school dictionaries.

\footnotetext{
* Universidade Federal da Bahia, Salvador, Brasil, Doutor em Letras, Professor Associado I, americovenancio@gmail.com.
} 


\section{A VARIAÇÃO LINGUÍSTICA EM DICIONÁRIOS ESCOLARES: O ESTADO DA ARTE}

Vosmecê agora me faça a boa obra de querer me ensinar o que é mesmo que é: fasmisgerado... fazmegerado... falmisgeraldo... familhas-gerado...?

(ROSA, 1988, p. 13).

\section{INTRODUÇÃO}

"Nonada” não terá sido 'qualquer argueiro' ou 'coisa de nada', para o leitor que, pela primeira vez, tivera tido o privilégio de ler a imortal obra de Guimarães Rosa, Grande Sertão: veredas. No primeiro parágrafo, eram léxico, um ponto e mais nada. Que significado teria aquela palavra isolada por um sinal de pontuação, que servia de abre-alas para uma narrativa tão excepcionalmente brilhante que a sucederia?

Talvez seja lícito conjecturar que esse alegado leitor tivesse tido o mesmo sentimento de desconforto - por assim dizer lexical - de Damázio, aquele cavaleiropersonagem a quem Rosa empresta a literatura para "preguntar ... uma opinião ... explicada", no seu conhecido texto, intitulado "Famigerado", cujo excerto se apeou ou como preferem alguns - desapeou como epígrafe deste trabalho.

Pois é. É o léxico uma famigerada entidade linguística - em todas as acepções concordantes ou dissonantes que esse modificador possa comportar -, "cabismeditado" para alguns, 'altiloquente', para outros, quiçá ou até historicamente, 'afásico', para os utentes de línguas ágrafas.

Mas é, também, o léxico em uso muito mais do que os dicionários têm registrado em seus, cada vez mais crescentes, volumes impressos e - não menos densos em bytes arquivos e plataformas lexicográficas digitais. O desenvolvimento da lexicografia moderna, fortemente estimulado pela tecnologia informática, tem-se fundado na composição de corpora, de variegados tipologia e gênero e de expressivo número de textos, escritos e falados, no afã de tornarem-se cada vez mais representativos seus resultados quanto aos usos linguísticos reais. 
Não obstante esse esforço, a variação linguística nem sempre tem merecido o destaque que lhe deveria dar a comunidade de língua portuguesa, nomeadamente a brasileira, na proporção de sua multifacetada e pujante cultura e em razão da distribuição dialetal e diastrática, bastante condicionada por uma história de desigualdade social e econômica.

Para melhor compreender, com base empírica, como tem operado o registro sociolinguístico pela norma-padrão brasileira, no que concerne especialmente a seu léxico, pretende-se, pois, apresentar um breve levantamento sobre o tratamento dado à variação linguística em sete dicionários escolares, recentemente publicados no País, nomeadamente dos que têm os alunos do ensino médio como público-alvo original, com vistas a estabelecer um diagnóstico e, consequentemente, uma estratégia de ação, associada a um trabalho lexicográfico que veja na diferença de usos o rotor para a composição de dicionários dialetais ou socioletais.

\section{SOBRE A TIPOLOGIA ADOTADA NA ANÁLISE DAS OBRAS}

O Ministério da Educação (MEC) tem, através da Secretaria de Educação Básica (SEB), dado continuidade ao Programa Nacional do Livro Didático (PNLD), que estabelece como objetivo basilar prover as escolas públicas de livros didáticos, dicionários e outros materiais de apoio à prática educativa, a partir da avaliação e seleção de obras inscritas em conformidade com editais publicados especificamente para esse fim. Para tanto, em especial à avaliação de dicionários, desenvolveu o MEC uma tipologia que tem-se transformado em referência nacional para esse tipo de obra.

Neste trabalho, será adotada a mesma taxionomia tipológica, conquanto seja a avaliação do tratamento dado à variação linguística concentrada nos dicionários do tipo 4, isto é, nos originalmente destinados aos alunos do ensino médio. Destes, foram observados os seguintes títulos, todos na edição de 2011:

1. AUlete, Caldas (2011), Novíssimo Aulete dicionário contemporâneo da língua portuguesa. Rio de Janeiro: Lexikon.

2. BECHARA, Evanildo (2011), Dicionário da língua portuguesa Evanildo Bechara. $1^{\mathrm{a}}$ ed. Rio de Janeiro: Nova Fronteira.

3. BORBA, Francisco (ed.) (2001), Dicionário UNESP do português contemporâneo. Curitiba: Piá.

4. BORBA, Franscisco (2011), Dicionário de usos do português do Brasil. São Paulo: Ática.

5. DICIONÁRIO HOUAISS CONCISO (2011), São Paulo: Moderna.

6. QUADROS, Jânio da Silva \& ROSA, Ubiratan (2011), Novo dicionário da língua portuguesa. São Paulo: Rideel.

7. SACCONI, Luiz Antônio (2011), Grande dicionário Sacconi da língua portuguesa: Comentado, crítico e enciclopédico. São Paulo: Nova Geração. 


\section{COMENTANDO O COMPORTAMENTO DE CADA DICIONÁRIO NO QUE CONCERNE AO TRATAMENTO DA VARIAÇÃO}

\subsection{AULETE, Caldas (2011), Novíssimo Aulete dicionário contemporâneo da língua portuguesa. Rio de Janeiro: Lexikon}

Predominam, no dicionário, itens lexicais característicos do português brasileiro contemporâneo, quer nas entradas, quer nos demais textos da obra. São elementos que abrangem um universo bastante representativo e servem para ilustrar o cenário da diversidade cultural que caracteriza as unidades mais faladas, lidas e escritas pelos utentes brasileiros. A amplitude da seleção vocabular pode ser comprovada pela presença de entradas como "caju", "cajuí", "capim", "mandioca", "jabuticaba"; "manacá", "caçula", "cafuné", "dendê", "Iemanjá"; "acarajé" (originais de línguas africanas), além de neologismos lexicais do português brasileiro, como "mensalão", "boiola", "ricardão", "sacolão".

De igual forma, há registro de várias expressões idiomáticas, como: "acabar em pizza", "bater as botas", "cair bem", "picar a mula" etc, além de se registrarem vocábulos pouco usados, como "cafeteria" e "vassalo", ou elementos que já se encontram em desuso, a exemplo de "abacto" e "calaceiro".

No que concerne à inclusão de itens representativos da diversidade nacional, há muitos registros regionais, mas com distribuição irregular:

- NORTE: "arabu", "bacafuzada", "boi-bumbá", "buchada", “curiboca", “jerimum", "maracajá", "marambiré", "pacaia", "sairé”, "ticuanga".

- NORDESTE: "abará", "avexado", "chouto", "baião de dois", "bangalafumenga", "bodejar", "caboclinho", "cafuçu", "caroá", "curumba", "frigideira", "jequi”, "jerimum", "jiquipango", "macaxeira", maculelê", "munguzá", "murixaba", "quibebe", "quicé”, "rabichola", "tarrabufado".

- SUDESTE: "alojo", "burro sem rabo", "cabeça de porco", "canela de veado", "canjerê", "catopé", "lombada", mariposa", "pinel", "tiguera", "trem", "virado".

- CENTRO-OESTE: "bichar", "bitelo", "curau", "mantena".

- SUL: "boi na vara", "bombachas", "bombachudo", "changa", "chipa", "guampada", "guapo", "lombada", "milonga", "milongueiro", "paradouro", "parelheiro", "pavuna", "peleador", "perau”, "querência”;

Entre outros itens lexicais, com sentidos próprios a cada região do País, que certamente nem mesmo seriam reconhecidos por muitos habitantes de cada um desse espaços geográficos, em função de o uso ser às vezes característico de locais ou setores de atividades muito específicos. Ademais, alguns não são mais identificados como regionalismos, mas são circunscritos a apenas alguns estados da União.

Não obstante esses registros, optou-se por testar a funcionalidade do sistema remisso do dicionário, com vistas à compreensão de como o consulente poderia desvendar determinado regionalismo que pretendesse investigar. Observando-se, por exemplo, o 
verbete "manacá", antes citado, notou-se que, conquanto a etimologia indígena seja corretamente dada (do tupi), as remissões para "cangambá", "jeratacaca" e "manacácheiroso" são problemáticas. Em “cangambá”, por exemplo, não há - mesmo porque não deveria haver - remissão para "manacá", já que este se refere à área da botânica 'flor', enquanto aquele à da zoologia 'espécie de mamífero'. Ademais, em “cangambá" a remissão é para "jaritataca", diferente de "jeratacaca", que, estranhamente, não tem, como seria de se esperar, entrada própria no dicionário. Já em "jaritataca" a remissão a "cangambá" se dá no próprio enunciado definitório.

Esse problema fez com que se investigassem duas variantes lexicais deveras conhecidas da população brasileira: "abóbora" "jerimum". Nesta última, as marcas $N$. NE. (Norte/Nordeste) estão devidamente assinaladas na cabeça do verbete e a primeira acepção serve de remissiva: 'o mesmo que abóbora', a que segue nova remissão para "moranga". No verbete "moranga", há indicação remissiva para "jerimum", registro das variantes fônicas "moganga" e "muganga", mas nenhuma referência a "abóbora", em cujo verbete também não se detecta "moranga", mas duas variantes fônicas de "jerimum", a própria canônica e a forma desprestigiada "jerimu".

Não se esquece a obra de registrar formas variantes de certas unidades lexicais, como, por exemplo, "projétil" "projetil" e "negro" "nego", embora as variantes desprestigiadas apareçam como item complementar ao final da microestrtura do verbete.

\subsection{BECHARA, Evanildo (2011), Dicionário da língua portuguesa Evanildo Bechara.}

\section{$1^{a}$ ed. Rio de Janeiro: Nova Fronteira}

Embora a estrutura dos verbetes pressuponha a indicação de variantes fonológicas ou léxicas, há, todavia, ausência de algumas informações essenciais para a qualidade de uma obra de tipo 4, dentre as quais, pode-se citar a explicitação do tratamento dado aos africanismos, aos regionalismos, aos brasileirismos e às marcas de linguagem.

A inclusão de africanismos e indigenismos, por exemplo, está bastante presente na obra em análise, como em "acarajé", "cafuné", "camundongo", "maculelê", conquanto alguns estejam diretamente relacionados etimologicamente às línguas de origem, muitas vezes são tratados como meros africanismos. No que toca aos indigenismos, a obra não traz, em nenhuma das listas de abreviaturas, uma que se refira a étimos indígenas. Não obstante, os elementos indígenas são apresentados como de étimo tupi, como em "acapu", "biaribi", "cajá", "maitaca", "onfuá".

Ademais, há o registro dissonante de inúmeras lexias que são, largamente, difundidos como provenientes de línguas africanas, mas que são apresentadas com a marca de brasileirismo, "cafuné”, “caxambu”, "jabaculê", "marimbondo", "moqueca", "muamba”, "quilombo", "senzala", entre outros.

A inclusão de regionalismos é frequente na obra, sendo possível apresentar, por região, lista exemplificativa de verbetes, ressalvando-se que a menos representativa, em termos de ocorrência, é a Centro-Oeste:

- NORTE - “arabu”, “aruanã”, “jerimum”, “bidó”, "buchada”, "corroló", "curadá", "curiboca"; "macaxeira", "munguzá" etc. 
- NORDESTE - "chouto", "baião de dois", "bambiá", "bedegueba", "bolo de rolo", "brote", "caboclinho", "caroá", "empachado", "frevioca", "jequi” etc.

- SUDESTE - "burro sem rabo", "canela de veado, "catopé", "cobu", "feijão-virado", "jembê", "lombada", "ticumbi", "virado" etc.

- CENTRO-OESTE - "arranca-língua", "atiçu", "chipa", "curau”, "derrame”, "mantena" etc.

- SUL - "bombachas", "changador", "dom-dom", "lombada", "mesquinhador", "milonga", "paradouro", "parelheiro", "pavuna", "peleador", "perau", "querência", "quipoqué" etc.

Observando o verbete "mexerica", não apresenta o dicionário uma definição própria, mas se serve antes das variantes lexicais "tangerina", "mimosa" e "bergamota", sem qualquer informação adicional. No verbete "mimosa", a segunda acepção apresentada é a de 'fruto da tangerineira'; 'tangerina'. Já em "tangerina", opta por uma definição lexicográfica, indicando se tratar de 'fruta cítrica cuja casca se solta facilmente', a que sucedem "bergamota", com indicação de uso regional (SC, RS), e as remissões a "mexerica" e "mimosa".

Os dados do Projeto ALiB (Atlas Linguístico do Brasil), cujos resultados já se prenunciam, poderão contribuir para o conhecimento mais preciso de isoléxicas no cenário linguístico brasileiro.

\subsection{BORBA, Francisco (ed.) (2011), Dicionário UNESP do português contemporâneo.}

\section{Curitiba: Piá}

Revela-se um dicionário eminentemente voltado para o registro dos usos do português contemporâneo. Um exemplo significativo é o do verbete "dar", que apresenta várias expressões idiomáticas de uso corrente no Brasil - "dar-se ao luxo", "dar bode", "dar brecha", "dar colher de chá", "dar com os burros n'água", dentre tantas outras.

No que se refere à diversidade, pode-se afirmar que a realidade brasileira é considerada sem desrespeito à alteridade, por omissão, como se pode perceber, por exemplo, nas várias entradas que se referem a elementos de diferentes manifestações religiosas: "padre", "pastor", "pai de santo", "pajé", "catolicismo", "umbanda", "seicho-noiê", "candomblé", "espiritismo", "kardecismo", "protestantismo", "judaísmo", "budismo", "evangélico", "muçulmano", "nirvana”, "axé”, "orixá", "exu”, "macumba”, "arcebispo", "arquidiocese", "batismo", "reencarnação", "médium", "islamismo", "maometano", "meca", "sinagoga", "maná", "pentecostalismo", "evangelismo", "testemunha de jeová", "taoismo", com tratamento lexicográfico correlato, embora em dois casos, especificamente, se identificaram graves imprecisões definitórias, como em "exu" e "candomblé", que necessitam ser corrigidas, sob pena de se difundirem conceitos equivocados sobre a questão.

O dicionário não explicita suas bases teóricas em nenhum dos seus paratextos. $\mathrm{Na}$ "Introdução", menciona apenas o VOLP (Vocabulário Ortográfico da Língua Portuguesa) e o banco de dados do Laboratório de Lexicografia da UNESP (Campus de Araraquara), usados, respectivamente, como referência para a solução de questões gráficas e para a 
seleção dos corpora. Apesar dessa omissão, pode-se inferir que trabalha com a teoria da variação e da mudança linguística. Não obstante, as questões relacionadas às variantes fônicas muito comuns no português brasileiro ainda não encontram acolhida na obra. Em "rubrica", por exemplo, não se faz qualquer comentário sobre uso desprestigiado de "rúbrica" (proparoxítona), mas muito comum no Brasil. Como se sabe, segundo a visão conservadora, esta última forma estaria em desacordo com o comportamento fônico das vogais longas latinas no processo de constituição do português, já que só se deslocariam à sílaba anterior os elementos silábicos cuja vogal fosse breve, o que não é o caso. Mas não são os homens que "fazem a língua, e não a língua os homens", como diria Fernão de Oliveira $(1975$, p.43)?

O dicionário faz, entretanto, o emprego de dois pontos como indicadores da variação de pronúncia entre ditongo e hiato, em vocábulos do português - como se pode observar nos verbetes "ruidoso" e "fólio", cujas cabeças de verbete trazem como item estrutural a informação de separação silábica: "ru:i.do.so" e "fó.li:o", atentando para uma questão de difícil definição no PB.

Tratando-se da inclusão de regionalismos representativos da diversidade nacional, na Apresentação do dicionário, adverte-se que "se registraram os regionalismos que se conseguiu identificar e os estrangeirismos" (p. VIII). É o caso de "muchacho", "chimango", “cusco" (Reg: RS); "macaxeira", “aipim”, "capote2” (Reg: NE)". São, entretanto, muito raras essas marcas no dicionário. Procuraram-se, ao acaso, alguns regionalismos conhecidos, mas estes não estão assinalados como tais. É o caso de "periguete", um regionalismo baiano.

Embora a inclusão de indigenismos e africanismos não seja uma exigência para dicionários do tipo 04 nos editais do MEC, em explícita dissonância com o que determina a Lei 11.645/2008, que zela pelo ensino da história e cultura africanas e indígenas na Educação Básica, foi possível observar a inclusão de vários itens provenientes de línguas africanas, como em "camundongo", "murundu", "marimbondo", "malungo", "bunda", "candombe", "candomblé", e indígenas, a exemplo de "cambuí", "gabiroba", "juriti", "jurubeba", "mandioca", "mandi", "tipoia". Inobstante esses registros, resumem-se a "africanismos", apenas, sem qualquer referência explícita à real etimologia, como seria de se esperar. Medeiros (2008, p.37) já havia alertado, em seu trabalho, para o "elevado número de elementos lexicais rotulados como meros africanismos", nos principais dicionários brasileiros, o que, para ela "denota a falta de precisão das informações etimológicas de itens lexicais tidos como oriundos de línguas africanas" e, consequentemente, desrespeito histórico.

Conforme se lê na página X, do texto "Introdução": "As palavras provenientes do tupi também são rotuladas, (sic) e as provenientes das diversas línguas africanas se rotulam simplesmente como Africanismo (Afr.)". Ao rotular os africanismos de forma generalizada, acaba por desconsiderar a diversidade étnica e linguística do continente africano, não contribuindo, assim, para o estudo da história da África, no Brasil. Note-se que os dicionários jamais rotulam de "europeísmo" qualquer item de línguas europeias, mas, sim, de "galicismo", "anglicismo" etc, demonstrando-se descompasso e pesos distintos de prestígio linguístico entre as línguas dos dois continentes.

Embora isso não esteja explicitado na apresentação da obra, há pelo menos dois sistemas de remissão: um indicado pela abreviatura " $\mathrm{Cp}$ " (compare) e outro feito por meio 
de indicações de lexias em negrito ao final do verbete, para casos de vínculo semântico, como sinonímia, antonímia, homonímia etc., ou de variação linguística. De modo geral, esse sistema de remissões é eficiente, como se pode constatar em verbetes como "mamaluco"/"mameluco", "buganvília"/"primavera"2". Registram-se, também, variantes gráficas em entradas diferentes, como "cotidiano"/"quotidiano", "dedodurismo"/dedurismo", "verdoengo/verdolengo", "veredito/veredicto", "choutar/choutear" etc.

As variantes de pronúncia, como algumas já citadas "marimbondo"/“maribondo", "mamaluco"/“mameluco", "gabiroba"/"guabiroba", "quebranto"/“quebrante", "madorra"/"modorra", "cabine"/“cabina", "câmera"/“câmara", "bambual"/“bambuzal", aparecem lado a lado, na entrada do verbete, assim como remissivamente, o que facilita a pesquisa do consulente. A abertura das vogais tônicas "e" e "o" é indicada entre colchetes, logo após a divisão silábica, como nos casos de oposição fonológica.

\subsection{BORBA, Francisco (ed.) (2011), Dicionário de usos do português do Brasil. São Paulo: Ática}

A variação linguistica no dicionário, no que concerne à inclusão de regionalismos representativos da diversidade nacional, é, segundo preconiza a "apresentação" da obra, realizada através da abreviatura $R e g$, advetindo-se que "a variação regional foi indicada sempre que ocorreu apenas em textos bem localizados regionalmente" (p. XI). É o caso de muchacho, chimango, cusco (Reg. S); macaxeira, aipim, capote (Reg. NE)". São, entretanto, muito raras essas marcas no dicionário. Procuraram-se, ao acaso, alguns regionalismos conhecidos, mas estes não estão assinalados como tais. É o caso de corixo, um regionalismo do MT e MS, ou de "periguete", muito comum na Bahia, hoje já difundido por todo o País. Um item simples e bastante exemplar da variação lexical brasileira, como "abóbora", desconhece no dicionário uma remissão para "jerimum", embora este item seja descrito exclusivamente por aquela variante e apresentado como Reg $N E$. Ademais, "caolho", um neologismo morfológico afro-brasileiro (quimbundo + português), não oferece qualquer remissão a "estrábico" ou mesmo a "zarolho", conquanto neste verbete esteja presente a definição sinonímica 'caolho', para sua decodificação semântica.

Inúmeros neologismos diageracionais, que começaram a circular na língua e se consolidaram como unidades lexicais, seja como resultado do avanço tecnológico (estrangeirismos), seja em virtude do acréscimo de novos semas a palavras já existentes (neologismos semânticos), inexistem no dicionário, a exemplo de "ficar", "namorar por algumas horas sem compromisso ou fidelidade', "irado", no sentido de "qualificação positiva relacionada a um fato, ocorrência ou objeto', "pancadão" ou "bolado", 'aborrecido, chateado', até mesmo "balada", enquanto 'divertimento noturno dos centros urbanos', e "torpedo", para 'mensagem curta enviada por meio de telefone celular'.

Nas definições, observa-se que há uma tentativa de isenção ao se identificar a variação de registro e o tom do discurso, mas muitos casos fogem a essa regra. Forte exemplo desse grave problema na obra é o caso de baianada, definida como 'ação própria 
de baiano'; 'fanfarronada', 'erro', 'gafe' ou 'patifaria', sem indicar o tom do discurso, como depreciativo.

Um caso interessante é o de "fraldinha", que é indicada como 'ceroula', embora em boa parte do País a primeira acepção fosse a de 'corte de carne bovina'. No verbete "coxão duro", que estranhamente não encontra seu correspondente "coxão mole" registrado na nomenclatura, como seria de se esperar, não há qualquer indicação da variação lexical existente no Brasil, já que em outras regiões esse corte de carne é conhecido por "chã de fora/chã de dentro", assim como o é o corte de carne conhecido por "lagarto", mas que em parte do Nordeste, por "paulista".

\subsection{DICIONÁRIO HOUAISS CONCISO (2011), São Paulo: Moderna}

O Dicionário apresenta em sua nomenclatura diferentes níveis de variação linguística: formal ("lábaro"), linguagem informal ("granfa", "corno"), gíria ("pirado"), tabuísmos, expressões chulas ou grosseiras ou ofensivas ("xoxota"), linguagem pejorativa ("gentinha", “coroca"), linguagem infantil ("dodói"); para além de indicação de uso figurado ("veado", fig. e gros.), diacrônico ("calar", na acepção 'descer') e jocoso ("economês"). Há, ainda, o registro da área do conhecimento pertinente à entrada ("histerectomia" MED, "lactescente" BOT) e de regionalismos ("matintaperera"). Embora apresente uma lista de abreviações para as rubricas "antigo", "arcaico", "desusado", "obsoleto", "português arcaico", "pouco usado", são raras essas marcas no corpo da obra. Encontraram-se somente "anafrodisia", falta ou redução de desejo sexual', "anafrodita", 'aquele que não se interessa ou é insensível ao amor carnal ou ao sexo', e “grés”, 'arenito', marcadas como desusadas.

Em relação aos regionalismos, há registro de alguns vocábulos de uso tipicamente regional como "farolagem" e "galinha-morta", mas as unidades marcadas são raras. Encontra-se "potranca" (B.S.), mas essa mesma marca não aparece em "boleadeiras" ou "bagual". As unidades "aipim", "macaxeira", "muiraquitã" tampouco estão marcadas. Em "capote", falta a acepção referente ao regionalismo do Nordeste, a que corresponde "galinha d'angola".

Há também remissivas a ortografias alternativas, como em "cariboca" "curiboca". O sistema de remissões fornece remissivas para os parônimos. A indicação se dá por meio da abreviatura "cf." e de um símbolo. É o caso de "espiar/expiar", "descrição/discrição" etc.

Quando determinada palavra, locução ou acepção é de emprego exclusivo do Brasil (dialetismo vocabular ou semântico) ou é uma variante brasileira de uma palavra da língua, essa informação é dada ao leitor por pela marca B. Exemplo é o emprego da palavra "agito".

O dicionário contempla o vocabulário de diversas áreas do conhecimento e de diversos domínios discursivos especializados, como "vulva", "strogonoff", "femtoquímica", "fatorar" etc. Os africanismos e indigenismos não são marcados, como seria de se esperar, com as respectivas rubricas, como "cumari", "cunhã", "caxinguelê", por exemplo. Sua indicação se dá somente no campo da informação etimológica. 


\subsection{QUADROS, Jânio da Silva \& ROSA, Ubiratan (2011), Novo dicionário da língua portuguesa. São Paulo: Rideel}

Embora não se explicitem os critérios adotados para a seleção vocabular que conduziram a composição da obra, no dicionário é empregado o português brasileiro contemporâneo, já que estão presentes itens de origem a) tupi: "abacaxi”, "aipim", "caipora", "capim", "maracujá", conquanto inclua, equivocadamente, "moqueca", que como se sabe é de etimologia quimbunda; b) africana: "abará, "acarajé" (que de fato é uma incorparação morfossintática brasileira) "caçula", "moleque", "vatapá" e os verbos "cochilar" e "xingar". Especificamente em relação a elementos lexicais representativos do vocabulário das diversas regiões brasileiras, a variação linguística é em algum grau contemplada na obra, quer nos planos diatópico e diastrático, quer nas variações de registro. Um bom exemplo é o verbete "gente", que traz, na acepção 7, a informação "A gente: nós, quando falamos". Além disso, há também entradas para palavras e expressões próprias da oralidade, como "dedo-duro" e "dedurar".

Muitos verbetes indicam remissivamente a variantes regionais, a exemplo de "abóbora" e "jerimum", incluindo-se, ainda, variante fônica "jerimu", mas sem qualquer localização diatópica da ocorrência. Inobstante, não existe sistematicidade para esse tipo de indicação, já que em "semáforo" não se faz qualquer referência remissiva a "sinal" ou "sinaleira", sendo esta última variante inexistente no corpo do dicionário.

Ademais, observa-se que na perspectiva variacional semântica o dicionário traz como primeiras acepções para "rapariga" definições lusitanizantes: "mullher muito nova'; 'mulher no período entre a infância e a adolescência', revelando apenas na última acepção o sentido de 'prostituta', mais comum em algumas regiões do Brasil.

São também indicadas palavras pouco usadas (precedidas de abreviaturas diferentes, como p. us., Ant., Desus.), a exemplo de "alcaide", 'oficial de justiiça', "cifar", 'untar com azeite de peixe', "inanir" 'reduzir ao estado de inanição', "rêmige", 'que rema', "varoa”, feminino de varão', entre outros.

A obra traz também palavras ligadas à cultura juvenil, ao mundo do trabalho e à política, como "curtir", formas como "presidenta", ou mesmo estrangerismos como "impeachment". Não obstante, o dicionário não apresenta abonações nem exemplos, o que compromete seu uso pedagógico.

As variantes gráficas são indicadas e há remissão para a outra palavra por meio da marca de uso "Var." Em cada par, uma delas é explicada. São exemplos: "anchova" "enchova", "cascavelar" "cascavelhar", "marombar" "marombear", entre outros.

\subsection{SACCONI, Luiz Antônio (2011), Grande dicionário Sacconi da língua portuguesa: Comentado, crítico e enciclopédico. São Paulo: Nova Geração}

A obra afirma que é voltada para estudantes do ensino médio e serviria também ao ensino profissionalizante. Inobstante, não há qualquer informação sobre a caracterização do léxico desse público ou sobre os recursos que levaram a preparar uma obra voltada para esses estudantes. Encontra-se uma afirmação como sua "vasta seleção lexical inclui as palavras de uso comum hoje em áreas específicas (...), bem como regionalismos, gírias 
usadas pelos jovens e neologismos difundidos pela TV e pela Internet” (p. 5). O dicionário em análise apresenta uma seleção vocabular que, no geral, representa o português brasileiro contemporâneo. Há registros de palavras típicas da língua portuguesa do Brasil, tais como "balangandãs", “celular", "maracutaia", "mixuruca”, "pileque”, "pindaíba", "tchã", "cabra", com a acepção de 'pessoa valente', "cachaça", "ficha-limpa", entre outros. De modo geral, não se encontraram itens da variedade europeia da língua, como "equipa", "ficheiro", "pequeno-almoço", muito embora, estranhamente, o item "apelido", por exemplo, traga como primeira acepção 'nome de família', 'sobrenome', o que não corresponde ao português brasileiro. Além disso, o dicionário registra formas pronominais que não são comuns ao português brasileiro, como "lho" e "mo", aceitáveis, porém, por representarem elementos presentes na literatura nacional pregressa.

Sobre os regionalismos, encontram-se, por exemplo, entradas independentes para "macaxeira", "aipim" e "mandioca", mas sem qualquer indicação geoletal sobre esses usos. Ademais, "aipim” é definido pelas próprias variantes 'mandioca', 'macaxeira', mas no verbete "macaxeira" registra-se que "não se confunde com mandioca, tubérculo que possui algumas propriedades tóxicas". No verbete "mandioca", não se apresenta qualquer remissão a "aipim". Já em "jerimum" há a indicação de se tratar de item popular do N e NE, trazendo como definição sua própria variante-padrão, isto é, "abóbora". No verbete "bergamota", a indicação de uso regional de suas variantes é feita no próprio enunciado definitório, de forma enciclopédica, demonstrando certa assistematicidade do projeto lexicográfico da obra. Encontra-se no corpo do dicionário na definição do item "sacolé" suas formas variantes, como "brasinha", "chupa-chupa", "dim-dim" "dindim" (sem entrada própria no dicionário), "geladinho" (também sem entrada própria), "gelinho", conquanto sem qualquer referência ao espaço dialetal de uso.

Em casos em que aprece tácito o reconhecimento nacional da variação de uso quanto à tonicidade do item lexical, como em "ibero", "rubrica", "cateter", não existe qualquer registro ou advertência no dicionário. Variantes fônicas de outra natureza, originadas de metaplasmos, dissimilações etc., são identificadas, a exemplo de fiofó", em que há remissão à entrada "feofó", ou em "cariboca" "curiboca", para 'mestiço', não sendo, porém, tão regulares na obra.

\section{DISCUSSÃO SOBRE 0 ESTADO DA QUESTÃO}

Embora as observações sobre o tratamento da variação nos dicionários analisados tenham sido pontuais, em função da pouca disponibilidade de espaço própria ao gênero a que se condiciona este trabalho, pôde-se observar que a variação linguística registrada nessas obras é bastante seletiva, irregular, assistemática e timidamente sinalizada por algumas poucas marcas de uso.

Considerando que desde que a linguística moderna refinou o conceito de norma linguística, norma-padrão e normas de fala não mais se confundem. Reconhece-se, no Brasil, uma polarização sociolinguística, que divide diassistemicamente os hábitos da fala da população plenamente escolarizada, isto é, a de nível superior, dos daquela que convive alijada do espectro de práticas de letramento, relacionadas exclusivamente à modalidade escrita. Aos hábitos de fala de grande parte dos utentes da língua com escolarização 
incompleta ou sem qualquer grau de educação formal, convencionou-se chamar de norma vernácula ou popular.

O cenário sócio-histórico e a situação de multilinguístico generalizado, existentes nos primeiros momentos de transplantação da língua portuguesa para o Brasil, fizeram com que o fosso sociolinguístico entre os falantes escolarizados e não-escolarizados fosse "estruturando-se / como o frio dentro de um poço" - com a licença da poetisa - (Meireles 1983, p.107), desembuchando, hoje - para se apropriar aqui de um regionalismo bastante nordestino -, uma situação de pluralidade e polarização diastrática deveras peculiar (cf. e.g. Lucchesi, 1994), se se comparar essa realidade com a sua matriz europeia hoje em uso.

Essa polarização sociolinguística criou um efeito perverso no que se refere ao processo de socialização do ensino da língua portuguesa nas escolas do país, especialmente nas públicas, já que engendra uma situação de desequilíbrio danoso no que concerne ao acesso democrático ao processo de letramento. Considerando que as estruturas linguísticas das normas cultas, sobretudo em seus aspectos lexicais e morfossintáticos, estejam relativamente mais próximas das características reguladoras do padrão escrito do que daquelas das normas vernáculas, torna-se, obviamente, muito mais plausível o sucesso escolar para um aluno que tenha pais plenamente escolarizados e que esteja diariamente submetido a suas características de norma, do que para o aluno que conviva em comunidades onde, por exemplo, a regra seja a não-concordância interna do sintagma nominal ou a falta de acordo entre este e o sintagma verbal, como em "Os menino fala", formato morfossintático tão comum no país, ou de elementos lexicais como "motô", para 'motorista de ônibus', com implicações estigmatizantes, diastrático e diagenericamente, para além dos reflexos no pleno domínio do registro formal escrito por parte de seus utentes linguísticos. Isso para não se falar da questão socioeconômica, o acesso a bens e serviços e seus efeitos em cada um.

Ademais, no que concerne ao léxico, desconhecem-se ou omitem-se, como produtos linguístico-culturais de importância para a compreensão do processo formativo da língua, os formatos morfofônicos dos metaplasmos tão comuns desde a passagem do latim para o português, tais como próteses ou aféreses, epênteses ou síncopes, paragoges ou apócopes, rotacismos etc., muitas vezes desprezados no processo de registro escrito da história linguística do País. Considerando que verba volant, é tempo de se evitarem as perdas a que se submeteram as línguas naturais, no que concerne às formas linguísticas das minorias no processo de construção das línguas de cultura.

É claro que não cabe aos dicionários escolares o registro exaustivo desses elementos, mas já seria tempo de se estabelecerem estratégias pontuais que possam reverter, ao mesmo parcialmente, a assepsia imposta pela norma-padrão aos formatos linguístico-lexicais dissonantes, em especial os metaplásticos, em perspectiva escolar.

\section{POR UMA ALTERNATIVA GRECO-TROIANA DE REGISTRO DO LÉXICO}

Machado Filho (2010, p.62-63) registra em um de seus trabalhos que "enquanto em um dicionário geral da língua - "le serviteur de la tradition" (CATACH et al. 1971, p.17) por excelência - não pareça haver espaço para a inclusão de variantes que fujam ao status quo linguístico", defende, por outro lado, que, 
um dicionário dialetal, ao contrário, deve abarcar toda a instabilidade gráfica que os usos reais da fala possam em si fomentar, mesmo que esses itens não venham a constituir uma cabeça de verbete na nomenclatura principal, senão lemas secundários na sua microestrutura, além de elementos integrantes do índice de palavras (MACHADO FILHO, 2010, p.63)

Isso parece indicar que os avanços da linguística contemporânea, notadamente da lexicografia histórica e variacional, já deveriam a esta altura ter mais amplamente influenciado a indústria editorial, com vistas a um oportuno enfrentamento da variação linguística moderna de forma a romper com o modelo de exclusão praticado.

Não se pretende com isso recomendar que os dicionários de língua passem a contrariar seus procedimentos metodológicos, muito centrados na frequência dos dados e na composição de corpora com foco em material escrito, mas que se proponha uma pauta de construção de trabalhos lexicográficos voltados a investigar empiricamente a diferença linguística, sem se atribuirem valores sociais aos diferentes usos, possibilitando, sob a égide dessa perspectiva, a produção de vocabulários regionais da dialetação lexical e, oportunamente, de dicionários dialetais nacionais.

Um primeira tentativa nessa direção é a construção do Dicionário Dialetal Brasileiro, em andamento, que, com base nos resultados do Projeto ALiB (Atlas Linguístico do Brasil), pretende revelar aspectos curiosos da variação lexical nacional, sem desconsiderar os formatos fônicos que determinadas unidades lexicais possam assumir dialetalmente ou sociodialetalmente, a exemplo de "frosco", para "fósforo", ou "badogo" "badoge", para o formato canônico "badoque", de etimologia árabe.

A estrutura de um dicionário dialetal, como o que se propõe como pauta de investigação e produção, deve permitir o imediato reconhecimento, por parte do consulente, das variáveis espaciais e sociais registradas, para cada uma das variantes de seu interesse de pesquisa. A ideia é possibilitar um acesso rápido, a partir de uma microestrutura capaz de condensar essas informações, inclusive as variações fônicas dos itens lexicais, de forma prática e econômica, assim como permitir a identificação de possíveis relações lexicais e semânticas entre as lexias registradas.

Só assim as vozes "famigeradas" ou "falmisgeraldas", de falantes como as do personagem Damázio, poderão ser resgatadas e conservadas no esteio histórico de formação da língua portuguesa, no Brasil.

\section{REFERÊNCIAS}

AULETE, Caldas. Novíssimo Aulete dicionário contemporâneo da língua portuguesa. Rio de Janeiro: Lexikon, 2011.

BECHARA, Evanildo. Dicionário da língua portuguesa Evanildo Bechara. $1^{\mathrm{a}}$ ed. Rio de Janeiro: Nova Fronteira, 2011.

BORBA, Francisco (ed.). Dicionário UNESP do português contemporâneo. Curitiba: Piá, 2011. 
BORBA, Franscisco. Dicionário de usos do português do Brasil. São Paulo: Ática, 2011.

CATACH, Nina et al. Orthographe et lexicographie. Tome I. Paris: Didier, 1971.

DICIONÁRIO HOUAISS CONCISO. São Paulo: Moderna, 2011.

ROSA, João Guimarães. Primeiras Estórias. Rio do Janeiro: Nova Fronteira, 1988.

LUCCHESI, Dante. Variação e norma: elementos para uma caracterização sociolingüística do português do Brasil. Revista Internacional de Língua Portuguesa, 12, p. 17-28, 1994.

MACHADO FILHO, Américo V. L. Um ponto de interseção para a dialectologia e a lexicografia: a proposição de um dicionário dialetal brasileiro com base nos dados do ALiB, Estudos Linguísticos e Literários, 41, p. 49-70, 2010.

MEDEIROS, Carmen Lúcia de. Desfazendo as tranças: estudo renovado sobre a interferência das línguas africanas no léxico do português brasileiro. Trabalho de Conclusão de Curso. Salvador: Universidade Federal da Bahia, 2008.

MEIRELES, Cecília. Obra poética. Rio de Janeiro: Nova Aguilar, 1983.

OLIVEIRA, Fernão de. A gramática da linguagem portuguesa, Lisboa: Imprensa Nacional/Casa da Moeda, 1975.

QUADROS, Jânio da Silva \& ROSA, Ubiratan. Novo dicionário da língua portuguesa, São Paulo: Rideel, 2011.

SACCONI, Luiz Antônio. Grande dicionário Sacconi da língua portuguesa, São Paulo: Nova Geração, 2011.

Recebido em: 05 de março de 2014.

Aceito em: 08 de junho de 2014. 